\title{
Patient participation from the perspective of staff members working in spinal cord injury rehabilitation
}

\author{
Jeanette Melin ${ }^{1,2} \cdot$ Lars-Olof Persson $^{1} \cdot$ Charles Taft $^{1,2} \cdot$ Margareta Kreuter $^{3}$ \\ Received: 29 August 2017 / Revised: 20 December 2017 / Accepted: 24 December 2017 / Published online: 24 January 2018 \\ (c) The Author(s) 2018. This article is published with open access
}

\begin{abstract}
Study design Qualitative method, semi-structured interviews.

Objectives The aims of this study were to explore the meaning of patient participation from the perspective of staff members working with spinal cord injury (SCI) rehabilitation, and what they saw as requisites for and constraints to patient participation.

Setting Swedish spinal injury unit.

Methods Interviews with 13 staff members at a spinal unit were conducted individually and analyzed by means of content analysis.

Results One category describing patient participation emerged from the interviews: Patient - a team member. Four categories were extracted as requisites: Communication; information and knowledge; routines; respecting the patient as a unique person; and an open climate. Three categories of constraints were identified: Understaffing and new staff members; patients' inability to grasp information; and structures and fragmented responsibilities.

Conclusions The informants were unanimous in stating that the patient is an integral and natural member of the rehabilitation team. Recognizing the person with SCI as a team member acknowledges and endorses the patient as a person with capabilities to participate in his or her rehabilitation. The patient as a person also means that he or she has unique needs and preferences, which the staff members must accommodate. This is also fundamental in a person-centered approach. Therefore, the viewpoints of the informants may be useful for other settings to enhance person centeredness and patient participation.
\end{abstract}

\section{Introduction}

Patient participation is considered a core component of high-quality care [1] and is advocated by patient organizations [2], the World Health Organization [3], and the legislation [4]. Patient participation is also central to achieve high-quality person-centered care $[5,6]$, and has been found to be associated with improved self-care [7, 8],

Jeanette Melin

jeanette.melin@ri.se

1 Institute of Health and Care Science, Sahlgrenska Academy, University of Gothenburg, Gothenburg, Sweden

2 Gothenburg Centre for Person-Centred Care, Gothenburg University, Gothenburg, Sweden

3 Institute of Neuroscience and Physiology, Sahlgrenska Academy, University of Gothenburg, Gothenburg, Sweden better physical functioning $[9,10]$, and satisfaction with care [8, 10-12].

Health-care staff members have a great influence on patients' opportunities to participate in care and rehabilitation [13]. The staff members' ability to provide comprehensible and timely information to patients is vital for patients to be able make knowledgeable decisions about their care and treatment [14-18]. For patients to make use of the knowledge, it is important that staff members deliver the information in a manner commensurate with patients' individual needs and abilities [15]. Moreover, the staff members need to get to know and respect the patients in order to build a close cooperative relationship [15, 18-20]. Cooperation is fostered by an inviting environment where staff members are genuinely attentive to the patient and the patients are recognized as human beings [18].

Some obstacles to patient participation exist. Organizational impediments, such as lack of time and resources, have been reported as common barriers [21-23]. 
Unwillingness among staff members to surrender power may also impede patient participation [14, 21, 22], e.g., inexperienced nurses may find it difficult to share power with the patients because of insecurity and a need to be in control [21]. Moreover, patient participation may also be limited by patient-related factors, such as the patients' health status, capabilities, and preferences [16, 17, 23-26]. Specifically, in acute phases and in emergency care patients might be too ill or weak to participate $[23,25]$, or unable to understand information [22]. Also, some patients may not feel sufficiently competent [23] or motivated to take an active role in their own care [13, 16, 27].

In rehabilitation, patients are encouraged to be engaged and to take part in their treatment [28, 29]. However, most research from a staff member's perspective on patient participation stems from the nursing literature. Less is known about patient participation from a staff members' point of view in rehabilitation contexts. A good setting to study this is in a spinal cord injury (SCI) unit. SCI injury often involves a long recovery period, has great implications for the injured person, and requires comprehensive rehabilitation in which a multidisciplinary team works together with the patient [30, 31]. The importance of patient participation in SCI rehabilitation has also been stressed and from a patient's perspective [17, 32, 33].

This study is a part of a larger project focusing on the meaning and evaluation of patient participation in rehabilitation. The present interview study was performed to address the lack of knowledge about how a staff views patient participation. The specific aims of this study were to explore, firstly, the meaning of patient participation among staff members working with SCI rehabilitation; secondly, the perceived requisites for encouraging patient participation; and thirdly, the experienced constraints to implement more patient participation.

\section{Methods}

\section{Informants}

Informants were purposively sampled to represent a broad coverage of professions at a Swedish spinal injury unit (associate nurses, registered nurses, physiotherapists, occupational therapists, social workers, and physicians) with at least some years of clinical experience.

\section{Procedure and analysis}

The interviews were conducted individually and lasted between 30 and $65 \mathrm{~min}$. The informants could choose the place and time for the interview: ten were held at the clinic, one at the informant's home, one at the informant's office, and one at a café. The interviewer (first author) was unknown to the informants and had not worked at the unit the informants were recruited from.

The interviews started with the open-ended question: "What does patient participation mean to you?" The informants were encouraged to freely express their views. When unsure about what the informants' meant the interviewer asked them to clarify and expand their lines of thought. Two additional questions were asked about their viewpoints regarding requisites for and constraints to achieving patient participation.

The interviews were tape-recorded and transcribed verbatim. Content analysis according to Krippendorpf [34] was used to extract categories of information from transcribed interview texts. This technique includes the following steps: (1) extracting units with relevant information (unitizing); (2) creating manageable subsets that represent all possible units (sampling); (3) transforming units to analyzable representations (recoding/coding); (4) replacing duplicates (reducing); and (5) bridging the gap between units and what they mean, refer to, entail, provoke, or cause (inferring).

Several measures were taken to ensure the trustworthiness of the study [35]. To ensure credibility, the analyses were performed independently by two of the authors (J.M. and M.K.), and then discussed jointly until consensus was reached. A summary of the analysis was sent to the informants for confirmation or modification in a process referred to as member checking [36]. Moreover, to assure dependability and minimize inconsistency due to change over time [35], all data were collected within 3 months.

The study complied with ethical guidelines of the Regional Ethical Review Board in Gothenburg.

\section{Results}

\section{Informants}

In total, 13 staff members were included: eight females and five men, 28-62 years old, of which six were rehabilitation staff (occupational therapists or physiotherapists), and seven were caring/medical staff (other professions), with 3-33 years of clinical experience from SCI rehabilitation.

\section{Overall findings}

All informants considered patient participation to be an integral and natural part of SCI rehabilitation. One category describing patient participation emerged, namely Patient $-a$ team member. Four categories describing requisites for patient participation (Communication; information and knowledge; routines; respecting the patient as a unique person; and an open climate) and three categories describing constraints (Understaffing and new staff members; patients' 
inability to grasp information; and structures and fragmented responsibilities) to patient participation were derived.

\section{Meaning of patient participation}

\section{Patient-a team member}

A view permeating all interviews was that the person with SCI was seen as a team member who should take part in all planning and decisions about his or her rehabilitation. The staff members underscored that they contributed clinical knowledge, while at the same time, learnt from patients.

The patient is part of the team, because anyway it's all about the patient. (Interview 7)

We meet along the way [...] We learn from them and they learn from us, from our experience. (Interview 4)

Patient participation means that you collaborate with the patient on everything [...] that you have a common goal. (Interview 3)

\section{Requisites for patient participation}

\section{Communication, information, and knowledge}

The informants stressed the importance of communicating information, instructions, and knowledge to the person with SCI about the injury and the rehabilitation process. This should also be done in a timely manner and tailored to each patient's individual abilities and needs. The patient needed information and knowledge in order to understand his/her new condition, to evaluate different alternatives, and to make conscious decisions. They underlined the need to periodically repeat such information to ensure that it was fully understood and appreciated.

Information and knowledge about what has happened to the patient and what the consequences can be for different options, so that you are conscious, so that it'll be a conscious participation. (Interview 7)

Information [should be given] from the very start, the patient is given the information again and again because it isn't easy to take in what has happened. (Interview 11)

Consideration of the time since injury [should be taken into account], when the patient is at all able to take in the information. (Interview 1)

\section{Routines}

Scheduled goal-setting meetings and an assessment checklist were mentioned as important tools for facilitating patient participation. Such forums were seen to ensure that the patient's voice was heard. They were viewed to encourage active involvement in identifying and making decisions about what was important for the person with SCI, and in specifying the goals of the rehabilitation. However, it was also considered important that routines at the unit are flexible enough to accommodate each patient's individual needs.

We do in fact have a system that fosters participation; I mean that you work in a system where we have regularly scheduled goal-setting meetings where the patient is involved. (Interview 5)

We have routines but they're still designed taking into account the person behind the patient, we usually follow the routines, but you can adapt them to individual patients. (Interview 11)

\section{Respecting the patient as a unique person}

Empathic and responsive staff members were viewed to be important for patient participation. The informants pointed out that the staff members should respect and accept the person with SCI as the unique person he or she is, and be sensitive to the patient's needs and preferences. They also stated that to achieve patient participation the staff members should be sensitive to both verbal and non-verbal communication, which was promoted by frequent meetings with the patient.

[We need to] keep in mind that this is a new patient. We have to be aware of this all the time, we have to listen to what this particular person wants and take it in and decide if it's ok to do what the patient wants. (Interview 12)

[We need to] to capture this to find the right path. It's not certain that what I think is important as a staff member, is the same as what the patient thinks is important. (Interview 3)

Oftentimes if you've had long treatment contacts and when you've met with the patient many times then you've developed an understanding of that person. (Interview 13) 
However, some informants also pointed out that for safety and medical reasons they sometimes had to ignore the patient's expressed wishes and desire to participate. In cases where the patient was in intensive care, anesthetized, or otherwise less receptive, a family member could sometimes step in for the person with SCI.

For purely safety or medical reasons there are things that you cannot let the patients decide about doing or not doing - it's too great a risk. (Interview 11)

[When patients are] not fully conscious and need emergency care then participation is difficult. At such times you have to take over in some way, but you still always have the patients' needs at the forefront so in that sense they participate even if they're not actively participating. (Interview 5)

\section{An open climate}

The informants said that an open climate fostered patient participation. By this they meant that they should take time to listen to the persons with SCI and encourage them to ask questions and express their own thoughts and viewpoints.

A climate in which the patient dares, wishes and can ask questions and be curious, feels that his/her voice is heard and understands what we do. (Interview 2)

It's mainly by listening to the patient and that the patient feels free to ask questions. [...] My role is mainly to strengthen the patient [...] make the most of the resources the patient has and have this as a starting point. (Interview 10)

\section{Constraints to patient participation}

\section{Understaffing and new staff members}

Understaffing and time constraints meant that only the patient's most urgent needs could be met and that opportunities for patient participation suffered. This also happened when competent and experienced staff members resigned and were replaced by new and inexperienced staff members.

People who've worked 10 to 15 years are very competent and if many of them quit then it takes time to train new ones. (Interview 4)

What I mean is life experience in general, through experience you get answers to a lot of questions.
Without experience then you simply believe, and you can never read your way to the answers, you can just read the guidelines. (Interview 3 )

\section{Patients' inability to grasp information}

Some informants stated that patient participation sometimes could be constrained because of personal characteristics, e.g., low acceptance of the injury, brain damage, cognitive impairments, or psychiatric illness. Some persons with SCI were also seen to require more time than others to adapt to the new situation and could therefore have initial problems to take in information.

Real participation can only be achieved if the patient him/herself is cognitively reasonably intact and understands what we say. (Interview 12)

The psychological aspects can vary along the way [...] [There are] different conditions for participation, how much you're able to do [...] To make too many decisions can be tiring; you might not have the energy. (Interview 9)

\section{Structures and fragmented responsibilities}

Poorly defined work responsibilities and poor coordination between different levels of care were seen to hinder the staff members in involving patients in decisions about discharge since such decisions were often made partly or entirely outside the unit. Strict daily routines, such as mealtimes or bladder and bowel regimes were also considered to sometimes restrict patient participation.

Right now there are two newly injured patients in the emergency room who are waiting to come up [to the ward], so you have to tell patients that they'll be discharged to another ward. (Interview 11)

I think a lot has to do with a lack of clarity about what the purpose of our work is. It is quite unclear what it is and what the aim is of the time we spend here, what our responsibilities are here and along the entire continuum of care. (Interview 9)

We're supposed to work to become person-oriented it's supposed to be individualized, but at the same time, the patients are supposed go to the bathroom at regular times to suit the department's routines and so on. (Interview 5) 


\section{Discussion}

The significance of patient participation was apparent in our results and corroborates the emphasis given to patient participation in SCI rehabilitation [30, 31]. Informants were clearly convinced that the persons with SCI are integral and self-evident members of the SCI rehabilitation team. The interaction, negotiation, communication, education, and exchange of information between the staff members and patients were considered as crucial in this respect. They viewed the staff-patient relationship as a partnership, where two experts collaborate. The person with SCI contributes with his or her experiences and preferences and the staff contribute with professional knowledge [37]. Acknowledgement of the person with SCI as a team member and partner also suggests that he/she should be viewed as a reasoning, feeling, and capable person [37], i.e., a person who is able to make choices affecting his or her life and contribute to the rehabilitation in a meaningful way [31].

Some of the requisites for and constraints to patient participation identified in this study have previously been reported in nursing literature [20, 21, 23, 25]. Despite differences in patient populations, settings, and professionals, there seem to be similarities about important requisites for patient participation. However, previous studies of patient participation have not reported scheduled goal-setting meetings as a requisite as clearly as this study does. Goalsetting meetings and checklists aimed to enhance that the patient's active participation are well established in SCI rehabilitation [9, 10]. Such routines, together with the acknowledgement of the patient as a team member may be transferable and useful for other settings to enhance person centeredness and patient participation.

Corroborating other studies [14-16, 18], we found that information that is adapted to the individual and delivered in a timely manner is indispensable for enabling patients to actively and meaningfully participate in decisions regarding their care and rehabilitation. Likewise, relevant information has also been reported by patients to be crucial for making progress in rehabilitation. Increased knowledge has also been reported to be associated with better coping [38-40]. However, some persons with SCI quickly understand what has happened to them and the consequences of their injury, whereas others require much more time to fully appreciate the trauma and to become receptive to new information [33, 41]. In line with findings from some nursing studies [23, 25], our informants stated that in the initial phase full patient participation could be difficult to achieve because of the patient's inability to grasp information. This necessitates that the information should be clearly stated and repeated. Furthermore, persons with SCI have also expressed that the first period after the injury is so arduous and stressful that they do not have enough energy to actively participate [17,
32, 33]. During this period, the staff members may take over and do things for the patient rather than together with the patient. However, the staff members must also be aware of the patient's changing abilities and increasingly engage him or her in the different rehabilitation activities [31, 33]. This need of flexibility in motivational work could be challenging for staff members to handle. For example, staff members may take it as a personal failure if they cannot motivate the person with SCI to take responsibility for his or her own rehabilitation.

To promote patient participation, the staff members stressed the importance of spending time together with the patient to get to know the person with SCI on a personal level. As Papadimitriou and Carpenter [31] point out, if the staff members spend time together with the patient it will not only help to build rapport and facilitate negotiations in planning and training sessions, but will also establish trust. On the other hand, our informants stated that lack of time may hinder the staff members from listening to and becoming sensitive to the patient's verbally and nonverbally expressed needs and wishes. Similarly, staff members' level of clinical experience was seen to play an important role in engaging persons with SCI to participate. Sahlsten et al. [21] have also suggested that inexperienced nurses may feel more insecure and, thus, have a greater need for being in control rather than sharing "power" with the patient. It is also possible that new staff members need to spend more time to perform medical tasks, and therefore have less time to socialize with the patient. Furthermore, inexperience may cause less confidence to talk freely with the patients about their current and future situation. Hence, new staff members need to be introduced and trained not only in medical routines, but also how to handle psychosocial circumstances and issues about team collaboration.

The informants stressed that they aspired to encourage and promote patient participation; however, they also emphasized that persons with SCI could not always participate in all decisions. The staff members complained of fragmented responsibilities between and within different links in the chain of care and the fact that they were only involved in certain phases of the rehabilitation and only had responsibility for a limited time period. This lack of coordination has been criticized as a general problem in Swedish health care [42, 43]. A Swedish Government Official Report on effective health care [43] declared that patients' participation in their own care must be increased. In this endeavor, the report recommended that collaborations across the care continuum must be improved, particularly for patients with severe health problems. Our study also indicated shortcomings in this area, particularly regarding patient participation in decisions on length of hospital stay, discharge, transfer, etc.

The staff members' views about participation in this study are largely similar to those reported by persons with 
SCI in an earlier interview study within the present project [17]. For instance, both the patients and the staff members stressed that the staff members should provide individually tailored information and that they should respect the patient as a unique individual. This means that both patients and staff members considered a person-centered approach to be highly important for participation. Both parts also agreed that patient participation depended on the patients' health status, vitality, and coping ability. When the patients' conditions improved the importance of active participation increased. However, patient-staff congruence in their views on patient participation has been less studied, particularly in SCI rehabilitation. Two reviews in other areas have reported some incongruences between patients and staff members $[26,44]$. For instance, a narrative synthesis from the physiotherapy literature concludes that a common failure is to match the patients' preferred role for participation in his or her rehabilitation [44]. Patients felt that they were not asked or listened to in planning and that they did not get enough information and/or clear explanations [44]. Another example is a challenge highlighted from medical wards; nurses had a greater desire for a more patient-inclusive approach than what the patients were capable of or preferred [26]. Hence, it would be of interest to also evaluate this in clinical encounters in SCI rehabilitation to identify potential disparities between patients' and staff members' viewpoints. This may help the staff members to accommodate the patient's needs and desires and thus support person-centered approach in rehabilitation.

There are some limitations with this study. First, this study provides knowledge about viewpoints from the staff, not necessarily how they actually work. Such information would preferably be gathered with other methods, e.g., interviews of patients/relatives or observations. Second, this study neither provides an assessment of discrepancies between staff and patients' views of patient participation, nor does it evaluate the impact on clinical outcomes. This means that we cannot draw conclusions about the effects (e.g., clinical outcome or patient experiences) of the crucial aspects of patient participation highlighted by the informants.

\section{Conclusion}

In conclusion, this study provides a staff member perspective on what patient participation means in SCI rehabilitation as well as requisites for and constraints to patient participation. A key finding was that the staff members were unanimous in stating that the person with SCI is an integral and natural member of the rehabilitation team. Acknowledging the patient as a team member implies that the patient is recognized and appreciated as a person with capabilities to participate in his or her rehabilitation. This also acknowledges his or her unique needs and preferences, to which the staff member must accommodate. Hence, the staff members stated that the patient must be respected as a unique person and receive individually tailored information in an open, fostering climate where the patient feels free to ask questions and express his/her own ideas. Such viewpoints, derived from staff members at a SCI unit, are essential for promoting a person-centered approach to rehabilitation and may be germane to other health-care settings.

Although overwhelmingly convinced of the merits and importance of patient participation, the interviewees stressed that organizational and patient factors sometimes impeded their aspirations and ambitions to involve patients in all decision-making. Improved communication and coordination along the care continuum was seen as essential for ensuring patient participation in decisions regarding length of hospital stay, discharge, transfer, etc. Patient's impaired psychological state or cognitive ability as well as their own preferences for participation were mentioned as factors modulating the degree to which patients can participate in their rehabilitation.

Acknowledgements This work was supported by Norrbacka-Eugenia stiftelsen and University of Gothenburg Centre for Person-centred Care, GPCC.

\section{Compliance with ethical standards}

Conflict of interest The authors declare that they have no conflict of interest.

Open Access This article is licensed under a Creative Commons Attribution-NonCommercial-NoDerivatives 4.0 International License, which permits any non-commercial use, sharing, distribution and reproduction in any medium or format, as long as you give appropriate credit to the original author(s) and the source, and provide a link to the Creative Commons license. You do not have permission under this license to share adapted material derived from this article or parts of it. The images or other third party material in this article are included in the article's Creative Commons license, unless indicated otherwise in a credit line to the material. If material is not included in the article's Creative Commons license and your intended use is not permitted by statutory regulation or exceeds the permitted use, you will need to obtain permission directly from the copyright holder. To view a copy of this license, http://creativecommons.org/licenses/by-nc-nd/4.0/.

\section{References}

1. Institute of Medicine (U.S.). Committee on Quality of Health Care in America. Crossing the quality chasm (Elektronisk resurs) a new health system for the 21 st century. Washington, D.C.: National Academy Press; 2001.

2. Patient Empowerment Campaign. European Patients Forum. 2016. http://www.eu-patient.eu/campaign/PatientsprescribE/. Cited 22 Aug 2016. 
3. World Health Organization. Exploring patient participation in reducing health-care-related safety risks. Copenhagen: WHO Regional Office for Europé; 2013.

4. Patientlag (SFS 2014:821), Socialdepartementet. (Patient act. Ministry of Health and Social Affairs). Stockholm; Ministry of Health and Social Affairs, 2014.

5. Castro EM, Van Regenmortel T, Vanhaecht K, Sermeus W, Van Hecke A. Patient empowerment, patient participation and patientcenteredness in hospital care: a concept analysis based on a literature review. Patient Educ Couns. 2016;99:1923-39.

6. Kitson A, Marshall A, Bassett K, Zeitz K. What are the core elements of patient-centred care? A narrative review and synthesis of the literature from health policy, medicine and nursing. J Adv Nurs. 2013;69:4-15.

7. Hibbard JH, Mahoney ER, Stock R, Tusler M. Do increases in patient activation result in improved self-management behaviors? Health Serv Res. 2007;42:1443-63.

8. Näsström L, Jaarsma T, Idvall E, Årestedt K, Strömberg A. Patient participation in patients with heart failure receiving structured home care - a prospective longitudinal study. BMC Health Serv Res. 2014;14:633.

9. Kennedy P, Hamilton LR. The needs assessment checklist: a clinical approach to measuring outcome. Spinal Cord. 1999;37:136-9.

10. Byrnes M, Beilby J, Ray P, McLennan R, Ker J, Schug S. Patientfocused goal planning process and outcome after spinal cord injury rehabilitation: quantitative and qualitative audit. Clin Rehabil. 2012;26:1141-9.

11. Bieber C, Mueller KG, Blumenstiel K, Schneider A, Richter A, Wilke $\mathrm{S}$, et al. Long-term effects of a shared decision-making intervention on physician-patient interaction and outcome in fibromyalgia-a qualitative and quantitative 1 year follow-up of a randomized controlled trial. Patient Educ Couns. 2006;63: 357-66.

12. Holliday RC, Cano S, Freeman JA, Playford ED. Should patients participate in clinical decision making? An optimised balance block design controlled study of goal setting in a rehabilitation unit. J Neurol Neurosur Ps. 2007;78:576-80.

13. Longtin Y, Sax H, Leape LL, Sheridan SE, Donaldson L, Pittet D. Patient participation: current knowledge and applicability to patient safety. Mayo Clin Proc. 2010;85:53-62.

14. Cahill J. Patient participation: a concept analysis. J Adv Nurs. 1996;24:561-71.

15. Eldh AC, Ekman I, Ehnfors M. Conditions for patient participation and non-participation in health care. Nurs Ethics. 2006;13:503-14

16. Thompson AGH. The meaning of patient involvement and participation in health care consultations: a taxonomy. Social Sci Med. 2007;64:1297-310.

17. Lindberg J, Kreuter M, Taft C, Person LO. Patient participation in care and rehabilitation from the perspective of patients with spinal cord injury. Spinal Cord. 2013;51:834-7.

18. Thorarinsdottir K, Kristjansson K. Patients' perspectives on person-centred participation in healthcare: a framework analysis. Nurs Ethics. 2014;21:129-47.

19. Nordin C, Gard G, Fjellman-Wiklund A. Being in an exchange proces: experiences of patient participation in multimodal pain rehabilitation. J Rehabil Med. 2013;45:580-6.

20. Sahlsten MJ, Larsson IE, Sjostrom B, Plos KA. Nurse strategies for optimising patient participation in nursing care. Scand J Caring Sci. 2009;23:490-7.

21. Sahlsten MJ, Larsson IE, Plos KA, Lindencrona CS. Hindrance for patient participation in nursing care. Scand J Caring Sci. 2005;19:223-9.
22. Henderson S. Power imbalance between nurses and patients: a potential inhibitor of partnership in care. $J$ Clin Nurs. 2003;12:501-8.

23. Hoglund AT, Winblad U, Arnetz B, Arnetz JE. Patient participation during hospitalization for myocardial infarction: perceptions among patients and personnel. Scand J Caring Sci. 2010;24:482-9.

24. Coulter A, Ellins J. Patient-focused interventions: a review of the evidece. Europe: Picker Institute; 2006.

25. Frank C, Asp M, Dahlberg K. Patient participation in emergency care - a phenomenographic analysis of caregivers' conceptions. J Clin Nurs. 2009;18:2555-62.

26. Tobiano G, Marshall A, Bucknall T, Chaboyer W. Patient participation in nursing care on medical wards: An integrative review. Int J Nurs Stud. 2015;52:1107-20.

27. Wade D. Rehabilitation - a new approach. Part three: the implications of the theories. Clin Rehabil. 2016;30:3-10.

28. Gutenbrunner C, Ward AB, Chamberlain MA, Bardot A, Barat M, Bensoussan $\mathrm{L}$, et al. White book on physical and rehabilitation medicine in Europe. J Rehabil Med. 2007;39:1-48.

29. Wade D. Rehabilitation--a new approach. Overview and Part One: the problems. Clin Rehabil. 2015;29:1041-50.

30. Trieschmann RB. Spinal cord injuries. Psychological, social and vocational rehabilitation; Demos Publications, New York, 1988.

31. Papadimitriou C, Carpenter C. Client-Centered practice in spinal cord injury rehabilitation: a field guide; 2013.

32. Angel S, Kirkevold M, Pedersen BD. Rehabilitation after spinal cord injury and the influence of the professional's support (or lack thereof). J Clin Nurs. 2011;20:1713-22.

33. Scheel-Sailer A, Post MW, Michel F, Weidmann-Hügle T, Baumann Hölzle R. Patients' views on their decision making during inpatient rehabilitation after newly acquired spinal cord injury-a qualitative interview-based study. Health Expect. 2017;20: $1133-42$.

34. Krippendorff K. Content analysis. An introduction to its methodology. 3rd ed. Tpusand Oaks, USA: Sage Publications Inc.; 2013.

35. Graneheim UH, Lundman B. Qualitative content analysis in nursing research: concepts, procedures and measures to achieve trustworthiness. Nurse Educ Today. 2004;24:105-12.

36. Giacomini MK, Cook DJ. Users' guides to the medical literature: XXIII. Qualitative research in health care A. Are the results of the study valid? J Am Med Assoc. 2000;284:357-62.

37. Ekman I, Swedberg K, Taft C, Lindseth A, Norberg A, Brink E et al. Person-centered care-ready for prime time. Eur J Cardiovasc Nurs. 2011;10:248-51.

38. Parashar D. The trahectiry of hope: pathways to find meaning and reconstructing the self after a spinal cord injry. Spinal Cord. 2015;35:565-8.

39. Middleton J, Nocholson K, Craig A. A clincial perspective on the need for psychosocial care gudielines in spinal ford injury rehabilitation. Int J Phys Med Rehabil. 2014;2:226.

40. Consortium for Spinal Cord Medicine. Early acute management in adults with spinal cord injury: a clinical practice gudielline. J Spinal Cord Med. 2008;31:408-79.

41. Oliver M, Zarb G, Silver J, Mooore M, Salisbury V. Walking into darkness: the experience of spinal cord injury. UK: Palgrave, 1988

42. Docteur E, Coulter A. Patientcentrering i svensk hälso- och sjukvård: en extern utvärdering och sex rekommendationer för förbättring. Solna: Myndigheten för vårdanalys; 2012.

43. Effektiv vård: slutbetänkande. Stockholm: Wolters Kluwer; 2016.

44. Schoeb V, Burge E. Perceptions of patients and physiotherapists on patient participation: a narrative synthesis of qualitative studies. Physiother Res Int. 2012;17:80-91. 